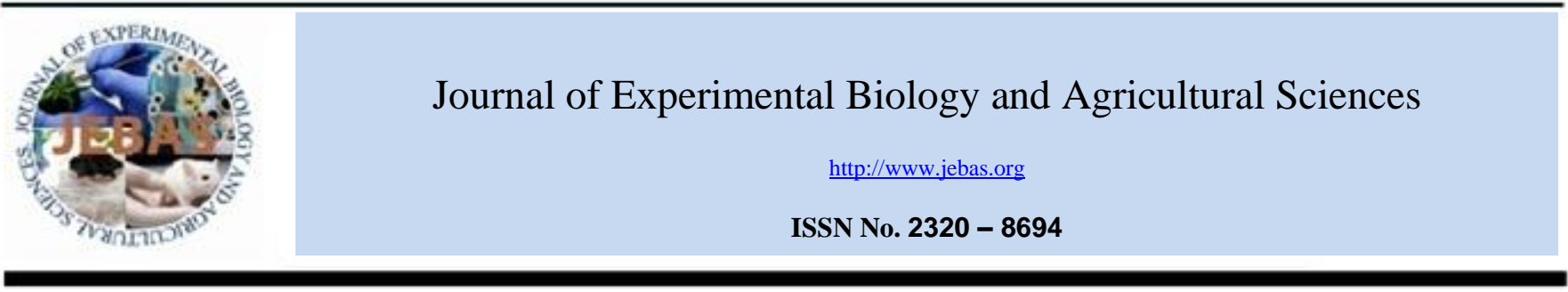

\title{
ASSESSMENT OF DROUGHT TOLERANCE IN FEW CLONES OF NATURAL RUBBER (Hevea brasiliensis) UNDER DRY HOT CLIMATE OF ODISHA, INDIA
}

\section{Krishan B}

Rubber Research Institute of India, Regional Research Station, Dhenkanal 759 001, India

Received - November 25, 2016; Revision- December 22, 2016; Accepted - January 15, 2017

Available Online - February 28, 2017

DOI: http://dx.doi.org/10.18006/2017.5(1).106.110

\begin{abstract}
KEYWORDS
Hevea brasiliensis

Clones

Drought

Tolerance

Climate

Odisha

ABSTRACT

A preliminary study was conducted to assess the drought tolerance at the early stages of growth in different clones of natural rubber (Hevea brasiliensis) at the Regional Research Station of Rubber Research Institute of India at Kadalipal, Dhenkanal, Odisha in eastern region of India. Poly bag plants of five clones RRII 430, RRII 105, RRIM 600, RRII 208 and IRCA 111 were assessed for the drought tolerance and compared drought injury indices status with same clones growing naturally in the adjoining field. Results of drought injury indicated scorching, leaf yellowing, drying and leaf fall at regular intervals, since imposition of drought stress conditions. Among various tested clones RRIM 600 and RRII 430 have comparatively higher drought tolerant. Plants under field condition showed drought injury symptoms much later than the poly bag plants. Drought indices, tolerance of drought of different clones and possible reasons have been also discussed.
\end{abstract}

Eastern region
* Corresponding author

E-mail: drbkrishan@gmail.com (Krishan B)

Peer review under responsibility of Journal of Experimental Biology and Agricultural Sciences.

Production and Hosting by Horizon Publisher India [HPI] (http://www.horizonpublisherindia.in/).

All rights reserved.
All the article published by Journal of Experimental Biology and Agricultural Sciences is licensed under a Creative Commons Attribution-NonCommercial 4.0 International License Based on a work at www.jebas.org.

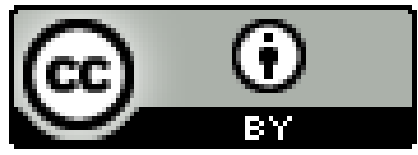




\section{Introduction}

The Para rubber tree (Hevea brasiliensis) is a tropical tree native to hot and humid Amazon region. Tree is commercially cultivated in south Asian countries, where the agro climatic conditions are suitable for its growth and productivity. Annual rainfall varying from 2000 to $4000 \mathrm{~mm}$, which is well distributed throughout the year, warm and sunny days with a temperature range of $21^{\circ} \mathrm{C}$ to $35^{\circ} \mathrm{C}$ and atmospheric relative humidity of 80 percent or above are considered to be best (Verheye, 2010). Further, fairly deep soils with slight to moderate acidic $\mathrm{pH}$ are also ideal for the growth of the tree (Rao \& Vijayakumar, 1992; Krishnakumar, 1993). Traditional rubber belt $\left(8^{\circ}-12^{\circ} \mathrm{N}\right)$ encompasses the southern tips of the peninsula in the country provides most appropriate environment conditions.

The shrinkage in the availability of cultivable land in the traditional region $\left(8^{\circ}-12^{\circ} \mathrm{N}\right)$ and ever growing demand for natural rubber has necessitated considering other areas of diverse agro-climate zone for the extension of rubber. The Odisha state $\left(17^{\circ}-22^{\circ} \mathrm{N}\right)$ located in eastern region of India was consequently identified as possible potential nontraditional region (Hajra \& Potty, 1986; Sethuraj et al., 1989).

The state experiences low and erratic rainfall, high temperature and low atmospheric relative humidity for about five to six months in a year (Gupta et al., 2002; Krishan, 2013). It is well quoted that these environmental conditions inhibits the growth and productivity of natural rubber (Chandrashekar et al., 1990; Mohankrishna et al., 1991). The needs of successful productive cultivation of rubber under less congeal area as of Odisha and other regions have necessitated screening and evolving clones for the drought prone conditions. The present early assessment of drought tolerance of few promising clones of rubber is a preliminary attempt towards the direction.

\section{Materials and Methods}

A preliminary study to assess the drought tolerance of five clones of natural rubber $(H$. brasiliensis $)$ was carried out at the Rubber Board, Regional Research Station at Kadalipal, Dhenkanal, Odisha $\left(20^{\circ} 49^{\prime} \mathrm{N}\right.$; $\left.85^{\circ} 30^{\prime} \mathrm{E} ; 100 \mathrm{~m} \mathrm{MSL}\right)$. The study was conducted during March to April 2010. Nine months aged brown budded poly bag plants with equal representation of twelve seedlings of five clones viz. RRII 430, RRII 105, RRII 208, RRIM 600 and IRCA 111 were undertaken for the study and also assessed the natural growth performance of same clones of twelve month age growing in the adjoining field. The field had plain terrain with acidic soil classified as loamy sand in texture and lateritic in nature. The weather parameters viz. maximum, minimum temperature and rainfall have recorded from meteorology observatory in Regional Research Station, kadalipal, Dhenkanal.

The entire experimental poly bag plants were provided with same cultural practices and environment. Further Poly bag were also filled with same field soil as acidic and loamy sand texture and of lateritic in nature. The plants of each clone were provided with shade and watering twice a week prior to impose drought stress conditions. Drought was imposed by discontinuing irrigation from the month of March 2010 onwards. Visual observations on drought injury parameters in leaves, as scorching, yellowing, drying and leaf fall were recorded at regular intervals, using the self calibrated of the four indices which are more suitable for monitoring and expressed in percentage. Similar observations were also recorded for same clones of twelve month stage growing naturally in adjacent field. The field plants were provided uniform standard cultural practices of rubber growing as described by Rubber Board (2009). The performance of poly bag and field plants with relevance to drought injury indices was assessed.

\section{Results and discussion}

The region experiences stressful drought for five to six months every year concomitant with high intensities of solar radiation and high temperature with an annual average rainfall of 1200.0 mm mainly confined mid June to September. The distribution of rainfall is far from the required amount for rubber cultivation which results in long dry spells extending from November to May causing drought conditions. The summer months, February to May exhibited severe soil moisture deficit. During the study average maximum temperature was exceeds than $35^{\circ} \mathrm{C}$, occasionally it rising beyond $44^{\circ} \mathrm{C}$ during the day in the summer months. Evaporation was low during July to September while it was higher during summer months (Gupta et al., 2002; Krishan, 2013). The mean temperature and rainfall of the study site during the experimental period has been given in Table 1 .

The drought symptoms in leaves were visually observed at regular intervals. The scorching symptoms were first noticed in RRIM 600 among the clones. The scorching symptom was observed during the initial stage of drought stress, between seven days after withholding of watering (Table 2). The early scorching in the clones seems to be mainly due to the high light intensity causing bleaching of chlorophyll. Further water stress which reduces the transpiration rate and increases leaf temperature may also results in leaf scorching (Jacob et al., 1999; Mohammadin et al., 2005).

Further leaf yellowing was noticed after twenty one days of water stress in the entire clones. Among the clones, RRIM 600 and IRCA 111 showed comparatively less yellowing (Table 2). Yellowing of leaves in all clones mainly attributed to water deficit in leave, creating an imbalance causing increase in ratio of carotenoids to chlorophyll (Serge \& Leonar, 2004). The better performance of few clones namely RRIM 600, IRCA 111 and RRII 430 may be due to comparatively efficient maintenance of leaf water potential and stomata conductance during the stress period (Chandrashekar et al., 1994). 
Table 1 Meteorological parameter of the study site.

\begin{tabular}{|c|c|c|c|}
\hline \multirow[t]{2}{*}{ Month/Period } & \multicolumn{2}{|c|}{ Temperature $\left({ }^{\circ} \mathrm{c}\right)$} & \multirow{2}{*}{$\begin{array}{c}\text { Rainfall } \\
\text { (mm) }\end{array}$} \\
\hline & $\operatorname{Max}$ & Min & \\
\hline 19.03 .10 to 25.03 .10 & $40.2(39.0-41.5)$ & $21.7(20.5-24.0)$ & 0 \\
\hline 26.03 .10 to 01.04 .10 & $40.1(38.0-42.5)$ & $24.4(25.5-25.0)$ & 0 \\
\hline 02.04 .10 to 08.04 .10 & $41.8(40.0-42.5)$ & $24.3(23.0-26.0)$ & 0 \\
\hline 09.04 .10 to 15.04 .10 & $43.1(41.0-44.0)$ & $25.2(23.0-27.5)$ & 0 \\
\hline 16.04 .10 to 22.04 .10 & $43.2(40.5-45.0)$ & $25.9(25.5-27.5)$ & 0 \\
\hline 23.04 .10 to 29.04 .10 & $42.0(41.5-43.5)$ & $25.7(24.5-26.5)$ & 0 \\
\hline
\end{tabular}

Table 2 Drought induced leaf symptoms of $H$. brasiliensis clones under polybag condition.

\begin{tabular}{|c|c|c|c|c|c|c|c|}
\hline \multicolumn{8}{|c|}{ SCORCHING $(\%)$} \\
\hline \multicolumn{8}{|c|}{ Days after introduction of drought stress } \\
\hline & 4 & 7 & 10 & 14 & 18 & 21 & 25 \\
\hline RRII 430 & - & - & 15 & 15 & - & - & - \\
\hline RRII 105 & - & 20 & 20 & - & - & - & - \\
\hline RRII 208 & - & - & - & - & - & - & - \\
\hline RRIM 600 & - & 15 & - & - & - & - & - \\
\hline IRCA 111 & - & - & - & - & - & - & - \\
\hline SE & - & 4.35 & 4.36 & 3.10 & - & 1.22 & - \\
\hline $\mathrm{CV}$ & & 1.24 & 1.25 & 2.01 & & 1.18 & \\
\hline \multicolumn{8}{|c|}{ YELLOWING (\%) } \\
\hline RRII 430 & - & - & - & 10 & - & - & 45 \\
\hline RRII 105 & - & - & - & - & - & 15 & 25 \\
\hline RRII 208 & - & - & - & 10 & - & 50 & - \\
\hline RRIM 600 & - & - & - & - & 5 & - & - \\
\hline IRCA 111 & - & - & - & 5 & - & - & - \\
\hline$\overline{S E}$ & - & - & - & 2.23 & 1.01 & 9.69 & 9.13 \\
\hline $\mathrm{CV}$ & & & & 0.89 & 1.98 & 1.49 & 1.30 \\
\hline \multicolumn{8}{|c|}{ DRYING (\%) } \\
\hline RRII 430 & - & - & - & - & 10 & 15 & 15 \\
\hline RRII 105 & - & - & - & - & 15 & 45 & 45 \\
\hline RRII 208 & - & - & - & - & 20 & 35 & 75 \\
\hline RRIM 600 & - & - & - & - & - & 20 & 35 \\
\hline IRCA 111 & - & - & - & 10 & - & 15 & 15 \\
\hline SE & - & - & - & 2.44 & 4.01 & 6.10 & 10.95 \\
\hline $\mathrm{CV}$ & & & & 1.20 & 0.88 & 0.47 & 0.61 \\
\hline \multicolumn{8}{|c|}{ LEAF FALL (\%) } \\
\hline RRII 430 & - & - & - & - & 5 & - & 15 \\
\hline RRII 105 & - & - & - & - & - & - & 25 \\
\hline RRII 208 & - & - & - & - & - & - & 55 \\
\hline RRIM 600 & - & - & - & - & - & - & 10 \\
\hline IRCA 111 & - & - & - & - & - & - & 15 \\
\hline SE & - & - & - & - & 0.47 & & 8.10 \\
\hline $\mathrm{CV}$ & & & & & 1.95 & & 0.68 \\
\hline
\end{tabular}


Leaf drying is an important drought symptom. Maximum leaf dryness was observed after twenty five days of stress induction in clones RRII 208 and RRII 105. The other clones also showed leaf dryness up to a certain extent. The possible high drought susceptibility was reported in RRII 208 and up to certain extent also reported in RRII 105. This may be due to higher water stress induced early senescence (Table 2). Leaf senescence and shedding also decreases the total leaf hydraulic conductance; following soil drying and root decay adversely affecting the root conductance (Sangsing, 2004). Further, the leaves of rubber trees tends to loss turgidity and expose the effective leaf area to direct sun causing drying of leaves (Chandrashekar et al., 1994). Stress also induced conditions which lead to less leaf area index, resulting in lesser solar radiation interception and plants shows comparatively poor growth (Devkumar et al., 1988). Leaf fall following commencement of dryness was also most predominant in RRII 208 and RRII 105.

The performance of clones in the field conditions is depicted in table 3. Among the various tested clones, clone RRII 208 followed by RRII 105 and RRII 430 showed higher scorching, yellowing and drying of leaves as compared to other clones. The clone RRIM 600 recorded the comparatively less drought symptoms and thus showed higher tolerance. The response of plants varied to drought in field and polybag conditions. The higher and delayed tolerance to drought injury under the field conditions as compared to the polybag plants seems to be mainly due to high soil volume and soil moisture storage associated with field plants. The present findings are in support with the earlier report under almost similar environmental conditions (Ravichandran et al., 2011).

Table 3 Drought leaf symptoms of $H$. brasiliensis clones under the field condition.

\begin{tabular}{|c|c|c|c|c|c|c|c|}
\hline \multicolumn{8}{|c|}{ SCORCHING $(\%)$} \\
\hline \multicolumn{8}{|c|}{ Days after introduction of drought stress } \\
\hline & 4 & 7 & 10 & 14 & 18 & 21 & 25 \\
\hline RRII 430 & - & 5 & - & 15 & 15 & 15 & - \\
\hline RRII 105 & - & - & - & - & 5 & 10 & 10 \\
\hline RRII 208 & - & - & - & 10 & - & - & - \\
\hline RRIM 600 & - & - & - & - & - & - & - \\
\hline IRCA 111 & - & - & - & 5 & 5 & - & - \\
\hline $\mathrm{SE}$ & - & 1.00 & - & 2.91 & 2.73 & 3.16 & 1.95 \\
\hline $\mathrm{CV}$ & & 1.97 & & 0.97 & 1.09 & 1.26 & 1.98 \\
\hline \multicolumn{8}{|c|}{ YELLOWING (\%) } \\
\hline RRII 430 & 10 & 10 & 15 & 15 & - & - & - \\
\hline RRII 105 & - & 10 & - & 25 & - & 25 & 25 \\
\hline RRII 208 & - & 10 & - & 10 & 20 & 25 & 40 \\
\hline RRIM 600 & - & 5 & - & - & 5 & 10 & 15 \\
\hline IRCA 111 & - & - & 5 & - & - & 10 & 15 \\
\hline SE & 1.95 & 2.01 & 2.91 & 4.74 & 3.87 & 4.84 & 6.59 \\
\hline $\mathrm{CV}$ & 1.97 & 0.57 & 1.45 & 0.95 & 1.54 & 0.69 & 0.68 \\
\hline \multicolumn{8}{|c|}{ DRYING (\%) } \\
\hline RRII 430 & - & - & - & 10 & - & 10 & - \\
\hline RRII 105 & - & - & 5 & - & - & 20 & - \\
\hline RRII 208 & - & 20 & - & - & 35 & 35 & - \\
\hline RRIM 600 & - & - & - & - & - & - & - \\
\hline IRCA 111 & - & - & - & & - & 5 & - \\
\hline SE & - & 4.01 & 1.00 & 2.00 & 7.10 & 6.20 & - \\
\hline $\mathrm{CV}$ & & 1.98 & 2.01 & 2.00 & 2.10 & 6.88 & \\
\hline \multicolumn{8}{|c|}{ LEAF FALL $(\%)$} \\
\hline RRII 430 & - & - & - & - & - & - & - \\
\hline RRII 105 & - & - & - & - & - & - & 10 \\
\hline RRII 208 & - & - & 20 & - & - & 25 & - \\
\hline RRIM 600 & - & - & - & - & - & - & - \\
\hline IRCA 111 & - & - & - & - & - & - & 5 \\
\hline SE & - & - & 3.98 & - & - & 4.84 & 2.01 \\
\hline $\mathrm{CV}$ & & & 2.01 & & & 1.61 & 1.33 \\
\hline
\end{tabular}


Clonal variation existed in the degree of tolerance of drought as well as in the response to irrigation as also reported by Chandrashekar, (1997). Inherited genetic, anatomical and physiological characters among drought tolerant and susceptible clones might be different and contributed to variability in tolerance (Premakumari et al., 1993). In general, clones RRIM 600 and RRII 430 showed comparatively higher tolerance to drought conditions.

\section{Acknowledgement}

The author is highly grateful to Director, Rubber Research Institute of India for providing necessary facilities and encouragement. The author also wishes to acknowledge the efforts of the field staff associated with the research work.

\section{Conflict of interest}

Authors would hereby like to declare that there is no conflict of interests that could possibly arise.

\section{References}

Chandrashekar TR (1997) Stomatal response of Hevea to atmospheric and soil moisture stress under dry sub humid conditions. Journal of Plantation Crops 25: 146-151.

Chandrashekar TR, Jana MK, Thomas J, Vijayakumar KR, Sethuraj MR (1990) Seasonal changes in physiological characteristics and yield in newly opened trees of Hevea brasiliensis in North Konkan. Indian Journal of Natural Rubber research 3: 88-97.

Chandrashekar TR, Vijayakumar KR, George MJ, Sethuraj MR(1994) Response of few Hevea clones to partial irrigation during immature phase in a dry sub humid climatic region. Indian Journal of Natural Rubber Research 7: 114-119.

Devkumar AS, Rao CG, Rajagopal R, Rao PS, George MJ, Vijayakumar KR, Sethuraj MR (1988) Studies on soil plant atmosphere system in Hevea: Seasonal effects and water relations and yield. Indian Journal of Natural Rubber Research 1: 46-60.

Gupta C, Rao KN, Edathil TT (2002) Seasonal performance of three elite Hevea rubber clones in a less favorably suited edaphic and climatic conditions of Orissa. PLACROYSM XV, 2002, Mysore, Karnataka, India, pp. 67-71.

Hajra NG, Potty SN (1986) Rubber Cultivation in North Eastern Region. Rubber Board Bulletin 22: 5-10.

Jacob JK, Annamalainathan K, Alam B, Sathik MBM, Thapliyal AP, Devakumar AS (1999) Physiological constraints for cultivation of Hevea Brasiliensis in certain unfavorable agro climatic regions of India. Indian Journal of Natural Rubber Research 12:1-16.
Krishnakumar AK (1993) Environmental factors that influence rubber plantation. International Rubber Digest 47: 12-13.

Krishan B (2013) Growth and early yield potential of a few RRII 300 series, IRCA and other clones of Hevea brasiliensis under the dry sub humid climate of Odisha, eastern India. Rubber Science 26: 250-258.

Mohankrishna T, Bhaskar CVS, Rao PS, Chandrashekar TR, Sethuraj MR, Vijayakumar KR (1991) Effect of irrigation on physiological performance of immature plants of Hevea brasiliensis in North Konkan. Indian Journal of Natural Rubber Research 4: 36-45.

Mohammadin R, Moghaddam M, Rahimian H and Sadeghian SY (2005) Effect of early season drought stress on growth characteristics of sugar beet genotypes. Turkish Journal of Agriculture and Forestry 29: 357-368.

Premakumari D, Pannikar AON, Marattukalam JG, Sethuraj MR (1993) Comparative bark anatomy of drought tolerant and susceptible clones of Hevea brasiliensis. Indian Journal of Natural Rubber Research 6: 10-14.

Rao PS, Vijayakumar KR (1992) Climate requirements. In: Sethuraj MR and Mathew NM (Eds) Natural Rubber: Biology, cultivation and Technology, Elsevier.

Ravichandran S, Meena S, Jacob J, Krishnakumar R and Annamalainathan K (2011) Drought tolerance of modern Hevea clones grown in the North Konkan region of Maharastra. Natural Rubber Research 24: 165-169.

Rubber Board (2009) Rubber and its cultivation. Rubber Growers Companian. Kottayam.

Sangsing (2004) Carbon acquisition and plant water status in response to water stress of rubber (Hevea brasiliensis Muell.Arg). Ph.D. Thesis submitted to the, Kasetsard University, Thailand.

Serge MB, Leonor A (2004) Die and let life: Leaf senescence contributes to plant survival under drought stress. Functinal Plant Biology 31: 203-216.

Sethuraj, MR, Potty SN, Vijayakumar KR, Krisnakumar AK, Rao PS, Thapliyal AP, Mohankrishna T, Rao CG, Chaudhuri D, George MJ, Soman TA, Meenatoor JR (1989) Growth performance of Hevea in the non-traditional regions of India. Proceedings of the Rubber Research Institute of Malaysia pp. 212-227.

Verheye W (2010) Growth and Production of Rubber. In: Verheye W (Ed.) Land use, land cover and Soil science, UNESCO, EOLSS Publishers. 